\title{
A Dinâmica da Integração Produtiva Asiática e os Desafios à Integração Produtiva no Mercosul*
}

\section{The Dynamics of Asian Productive Integration and some Challenges to South American Integration}

Carlos Aguiar de Medeiros**

Resumo: Objetiva-se neste artigo investigar a integração produtiva asiática e extrair algumas lições para o Mercosul nas últimas décadas. Demonstra-se que a conjugação de fatores estruturais, macroeconômicos e microeconômicos promoveu, no primeiro caso, uma integração produtiva virtuosa com elevado grau de crescimento econômico regionalmente articulado, ainda que com assimetrias na apropriação do valor e do progresso técnico. O maior contraste do Mercosul em relação à experiência asiática é a composição da pauta exportadora, vulnerabilidade externa de cada país do bloco e a inexistência de um importador líquido capaz de viabilizar a expansão de uma corrente de comércio compatível com a aceleração do crescimento econômico regional.

Palavras-chave: Integração produtiva. Regionalismo. Desenvolvimento econômico.

Abstract: This paper examines structural, micro and macroeconomic dimensions of the Asian productive integration in the last decades and explores some lessons for Mercosur. We argue that despite some asymmetries on value chain the conjunction of these dimensions had generated a dynamic and pro-growth integration. The contrast with the Mercosur is the composition of exports, the external vulnerability of each country and the absence of a net importer country. These factors are obstacles for an articulated expansion of regional trade and economic growth.

Keywords: Productive integration. Regionalism. Economic development.

JEL Classification: O24; F15.

* $\quad$ Este texto baseia-se numa pesquisa mais ampla - Integração produtiva: a experiência asiática e algumas referências para o Mercosul - elaborada para ABDI e CEPAL e apresentada no seminário internacional Integração produtiva: lições da Ásia e da Europa para o Mercosul, realizado em Brasília, em dezembro de 2008, e promovido por essas instituições. O autor agradece a assistência de pesquisa de Isabela Nogueira.

* * Professor associado do Instituto de Economia (IE) da Universidade Federal do Rio de Janeiro (UFRJ) e bolsista do CNPq. E-mail: carlosaguiarde@gmail.com 


\section{Introdução}

Um dos traços marcantes das últimas décadas foi o extraordinário crescimento do comércio mundial, aumentando o grau de articulação das economias nacionais à economia global. Indiscutivelmente, um dos principais fatores dessa expansão foi a desintegração ou fragmentação do processo produtivo, isto é, o fatiamento da produção e da cadeia de valor das mercadorias em diferentes países e regiões. Uma parte significativa do comércio internacional passou a se constituir de um fluxo de bens de uma mesma indústria internacionalmente distribuída.

O Leste e Sudeste asiáticos constituíram por excelência a região em que esse processo atingiu níveis mais altos, levando a formação de uma complexa e articulada rede de comércio e investimentos responsável por uma intensa corrente de comércio intrarregional. Esta expansão do comércio e dos investimentos se deu num contexto de alto crescimento econômico e deslocamento de especializações industriais entre as principais economias asiáticas. Fatores estruturais, macroeconômicos e microeconômicos concorreram para a afirmação da integração produtiva asiática que, ao contrário da regionalização europeia, teve menor presença de instituições de governo.

Objetiva-se neste texto investigar estes fatores da integração produtiva asiática e extrair algumas lições para o Mercosul, uma região com características tão distintas que a despeito de elevado índice de comércio intrarregional apresenta baixo grau de integração produtiva.

Além desta introdução, este texto está dividido em mais quatro seções. A segunda, discute os aspectos conceituais da integração produtiva e suas implicações para o desenvolvimento econômico; a terceira, analisa a integração produtiva asiática; a quarta discute a integração produtiva e o Mercosul, e a quinta resume e conclui o texto.

\section{A Integração Produtiva: Aspectos Conceituais e suas Implicações para o Desenvolvimento Econômico}

A integração produtiva resultou da internacionalização de um novo paradigma industrial distinto daquele vigente até os anos 70 que se baseava na produção verticalmente integrada (FEENSTRA, 1998). A desintegração vertical, isto é, a compra de matérias primas, bens intermediários, sobretudo de peças e componentes e serviços às empresas (ou outsourcing) afirmou um novo padrão industrial, inicialmente liderado pelo Japão na indústria eletrônica de consumo, mas rápida e agressivamente adotado pelas empresas industriais americanas. Este novo padrão 
produtivo generalizou-se na economia mundial naquelas indústrias em que o processo de produção pode ser segmentado em distintos e independentes estágios produtivos. A redução dos custos de transporte, a redução das barreiras protecionistas e a revolução na transmissão de informações e sua digitalização possibilitaram a codificação de processos produtivos e a sua modularização. ${ }^{1}$ Tais possibilidades originaram grandes fluxos de investimento produtivos voltados à busca de maior eficiência produtiva e redução de custos. A liderança de Empresas Multinacionais (EMN) nestas atividades deve-se aos elevados custos de administração e coordenação que esta estratégia de fragmentação possui, impondo elevadas barreiras de escala às firmas domésticas em países em desenvolvimento (UNCTAD, 2002). Tanto em setores de maior conteúdo tecnológico quanto em setores mais tradicionais - como vestuário - tornou-se possível padronizar determinadas atividades, separando-as daquelas não codificadas, proprietárias e lucrativas (STEINFELD, 2004). ${ }^{2}$ A política americana favorável à isenção tarifária de partes e componentes produzidos nos EUA embutidas em suas exportações e a meteórica expansão da produção industrial chinesa, com suas estratégias de processamento de exportações, através da modularização e outsourcing, ampliaram e aprofundaram esta nova arquitetura produtiva nos anos mais recentes.

Mas ao lado deste processo descrito pela formação de uma cadeia de mercadorias lideradas pelo produtor, formou-se outro, essencialmente criado pelas corporações americanas em suas relações comerciais com a China, que pode ser descrito como a formação de uma cadeia de mercadorias liderada pelo comprador em que grandes empresas de comércio varejista ou corporações associadas a um nome estabelecem um sistema descentralizado de produção e distribuição (HEINTZ, 2006).

Devido aos distintos processos subjacentes aos mecanismos de fragmentação produtiva, a sua mensuração não é tarefa trivial (GROSSMAN; HELPMAN, 2005), entretanto, independentemente de como defina-se o processo de fragmentação produtiva, o comércio de partes e componentes e de serviços às empresas é a sua expressão mais visível ora em curso na economia mundial. ${ }^{3}$ Mas, embora o comércio de partes

1 "Modularization is a method of manufacturing products from combinations of various components under a standardized interface without the need for adjustments so as to eliminate mutual incompatibility between the components. It provides such advantages as low cost and stable quality". (MIT, 2007, p. 168).

2 Observa-se em geral que as atividades com menores custos de transporte e comunicações e com menores barreiras regulatórias e tarifárias foram as mais adequadas a esta forma de estruturação. Entre essas, devido às suas características produtivas, a indústria elétrica e eletrônica tornou-se particularmente estruturada segundo as possibilidades abertas pela modularização.

3 Apenas recentemente a classificação da SITC permite a separação entre o comércio em 
e componentes seja um indicador relevante da internacionalização da cadeia produtiva induzida pelo produtor, ele pode denotar distintas dinâmicas e processos industriais. A rigor, a integração produtiva é um processo de combinação de processos produtivos desenvolvidos externamente à firma e nada diz a princípio sobre a especialização produtiva de um país ou, muito menos, sobre a integração produtiva regional.

Esta foi particularmente intensa nas últimas décadas. Seja por construção institucional, seja por razões macroeconômicas, seja por razões produtivas, o comércio intrarregional no Leste Asiático, na Europa, na América do Norte afirmou-se como o comércio mais dinâmico na economia mundial.

Assim, visando a extrair as implicações do processo de integração produtiva sobre a dinâmica regional, considerando em particular a experiência asiática, buscar-se-á descrever a integração produtiva liderada pelo produtor como um processo de especialização vertical (HUMMELS et al., 1998) no comércio internacional, que ocorre quando um dado país importa bens intermediários visando a uma exportação posterior numa cadeia sequencial até a produção de um bem final. ${ }^{4} \mathrm{~A}$ integração produtiva regional decorreria do grau em que esta especialização articula as distintas economias de uma região que se especializam em determinados estágios, tarefas e processos de produção.

Como observado em UNCTAD (2002), a produção fragmentada é uma forma particular de relações insumo-produto entre exportações e importações que tende a aumentar o conteúdo importado das exportações em relação ao valor adicionado. Esta questão é crucial para a trajetória de crescimento dos países e de sua integração regional. Com efeito, a expansão do comércio global e regional depende das sinergias e potencialidades que este promove para o crescimento das economias nacionais e embora haja uma via de mão dupla, não existe uma determinação mecânica e automática entre o crescimento do comércio e o

bens finais e o de partes e componentes e, ainda assim, apenas para alguns setores como máquinas e equipamentos de transporte. Para uma discussão, ver UNCTAD (2002).

Hummels, Rapoport e Yi (1998) afirmam que três condições precisam ocorrer para existir uma especialização vertical: um bem deve ser produzido em múltiplos estágios sequenciais; - dois ou mais países devem se especializar na produção de alguns, mas não de todas as etapas; - ao menos um estágio deve cruzar a fronteira internacional mais de uma vez. Usando este conceito - cujo índice pode ser calculado como o valor dos bens intermediários nas exportações de um país -, os autores observam, em primeiro lugar, a sua expansão geral na economia mundial, em segundo lugar, o predomínio da especialização vertical na química e nas máquinas e nos equipamentos, em terceiro lugar, a existência de uma menor especialização vertical nas economias grandes (EUA, Japão, Alemanha) e maior especialização nas economias menores. Este conceito é também útil para entender as razões para a rápida expansão recente do comércio de bens intermediários. Com efeito, o impacto de uma redução tarifária é muito maior sobre a especialização vertical devido ao seu impacto duplo sobre os bens intermediários embutidos nos bens finais. 
das economias. A conexão entre ambos depende do resultado final entre dois efeitos. De um lado, as importações de bens intermediários deslocam fornecedores locais, gerando um efeito negativo sobre o emprego e a renda; de outro, ampliam o acesso dos exportadores aos mercados externos com efeito positivo sobre estas variáveis. Deste modo, a questão chave para o desenvolvimento de um país é o grau em que a expansão das exportações industriais decorrente da integração produtiva permite expandir o valor adicionado industrial e consequentemente a renda interna. Se a expansão dos fluxos de comércio resultar em ritmos muito desiguais de crescimento entre países e setores produtivos (resultado da combinação desigual deste duplo efeito), a introdução de mecanismos de proteção aos distintos grupos e países possivelmente resultará numa redução do grau de integração.

Ainda que decorrente de processos estruturais e de mecanismos organizacionais, a integração produtiva envolve dois conjuntos de questões: uma macroeconômica e uma industrial. Com efeito, a expansão da corrente de comércio através da integração produtiva depende em larga medida da trajetória da balança de transações correntes dos países e, consequentemente, da evolução de seus passivos externos. Neste sentido, o fato da integração produtiva aprofundar o comércio vertical intraindustrial não tornam menos estratégicas variáveis macroeconômicas como a taxa de câmbio real, as tarifas de comércio externo e a taxa de juros. ${ }^{5}$

Do ponto de vista estrutural e tecnológico, as questões centrais do desenvolvimento de um dado país são a sua posição na hierarquia do valor adicionado da cadeia produtiva, as possibilidades de aprendizagem e mudança tecnológica e o grau em que esta inserção permite uma adequada taxa de crescimento da economia. Com efeito, a separação do processo produtivo favorece especialmente aos detentores dos ativos intangíveis (PEBD, desenho e concepção, marca, comercialização) na apropriação do valor adicionado, restando para as atividades padronizadas e de menor qualificação uma fração reduzida e submetida à elevada competição. ${ }^{6}$ Assim, a divisão vertical de trabalho organizada pelas EMNs gera importantes assimetrias entre países, conforme a sua especialização na cadeia de formação de valor, podendo constituir tanto

5 Como os contrastes observados no desempenho exportador asiático e mexicano ao longo dos anos noventa revelaram de forma eloquente.

6 "Networked modular production may create opportunities for the few players that actually can innovate, but for the vast majority who cannot- whether for reasons of inadequate resources, knowledge, $r$ supporting institutions- the terms of competition become brutal" (STEINFELD, 2004, p. 1974). 
uma possibilidade de desenvolvimento para os países de menor grau de desenvolvimento quanto uma armadilha. ${ }^{7}$

Assim, combinando as duas últimas questões - a da macroeconomia do crescimento econômico e a da mudança tecnológica -, deve-se considerar que a elevação dos salários reais ao longo do processo do desenvolvimento impõe um persistente deslocamento da especialização produtiva para etapas mais próximas à inovação e à diferenciação de produtos. Esta questão, que depende de recursos, pesquisa tecnológica e instituições, requer, por seu turno, uma razoável taxa de crescimento econômico. Uma integração produtiva e regional muito assimétrica pode vir acompanhada por um declínio da capacidade de importar das economias mais frágeis e crescente déficit comercial ampliando as restrições de balanço de pagamentos da economia e a paralisia dos investimentos necessários à mudança tecnológica. A superação deste impasse requer, desse modo, que a integração produtiva possua estímulos macroeconômicos indutores aos países de menor grau de desenvolvimento.

A questão essencial a considerar é de que maneira a integração produtiva e comercial numa dada área geográfica pode ser um estímulo maior à diversificação produtiva, mudança estrutural e ao progresso tecnológico do que a inserção em geral na economia internacional.

A análise da experiência asiática permitirá ilustrar estes aspectos.

\section{A Integração Produtiva Asiática}

As articulações entre integração produtiva e interdependência regional podem ser discutidas a partir de uma das análises mais conhecidas sobre o desenvolvimento industrial e a divisão regional do trabalho na Ásia - o esquema dos gansos voadores (EGV) - e o quanto este se mantém atual após a espetacular ascensão chinesa. ${ }^{8}$ Com efeito, o intenso comércio intra-asiático e a articulação regional de uma hierarquia entre o Japão, os Tigres Asiáticos (Coreia do Sul, Taiwan, Cingapura e Hong Kong), os quatro países mais dinâmicos da Associação das Nações do Sudeste Asiático (Asean-4) - Tailândia, Malásia, Indonésia e Filipinas -, a

7 "[...] the participation of developing countries in such production chains is not without problems and risks. First, increasing value added through technological upgrading and productivity growth in the context of international production sharing may prove to be more difficult than in selfcontained independent industries. Second growing competition among developing countries to attract FDI in order to enter such markets may lead to problems relating to fallacy of composition and provoke a race to button." (UNCTAD, 2002, p. 74).

8 O Relatório do Comércio e Desenvolvimento da UNCTAD de 1996 analisou os processos de industrialização no Leste Asiático a partir deste esquema, que segue sendo usado no relatório de 2007. 
China, e mais recentemente o Vietnã, sugere a formação de um esquema articulado de desenvolvimento. ${ }^{9}$

O EGV foi originalmente desenvolvido por Akamatsu $(1962)^{10} \mathrm{como}$ uma descrição da evolução industrial japonesa e da região asiática a partir de um encadeamento de fases sequenciais de importação, produção doméstica e exportação de bens hierarquizados segundo a sua complexidade tecnológica. ${ }^{11}$ Neste esquema, ao nível regional os países especializam-se de acordo com seus diferentes custos de produção. Os países mais atrasados começam importando determinado produto, para posteriormente produzir para o mercado local e, numa fase seguinte, exportar. Na linguagem de Akamatsu (1962), para cada produto há uma fase de heterogeinização e de complementaridade regional, sucedida por uma de homogeneização marcada pelo acirramento da concorrência e posterior heterogeinização. Em sua formulação original, Akamatsu (1962) vislumbrava um "ciclo do produto intra-setorial", através da expansão de novos produtos num mesmo setor de acordo com sua sofisticação tecnológica e um "ciclo de produto inter-industrial", com a passagem de bens de consumo para bens de capital. Cada ciclo envolveria as três fases, importação, produção doméstica e exportações (KASAHARA, 2004). Portanto, o EGV trata especialmente das mudanças nas especializações industriais, na qual a elevação dos custos de trabalho decorrente da absorção do excedente de mão de obra constitui um elemento central para o deslocamento das especializações. Ele apresenta para os países mais atrasados numa dada região dois tipos de estímulos: a focalização de objetivos (na compra de tecnologia, na produção e exportação de produtos) e uma alternância de complementaridade e concorrência (GINZBURG; SIMONAZZI, 2003).

Diferentes versões foram desenvolvidas sobre o EGV, uma das mais conhecidas, a de Kojima (2000) o descrevia como a formação de uma articulação harmoniosa, ${ }^{12}$ que levaria a um "catch-up do ciclo do produto”. Nesta versão, o IDE é o principal motor da reciclagem das

9 "It was the late Saburo Okita, a former Japanese Foreign Minister, who introduced the FG paradigm to a wider audience when he presented a speech at the fourth conference of the Pacific Economic Cooperation Council held in Seoul in 1985. After Minister Okita's speech, the FG paradigm rapidly gain popularity in the East Asian region, and has been thought to symbolize the Asian way of development integration." (KASAHARA, 2004, p. 7).

10 A ideia original do esquema é dos anos 1930 e foi usada explicitamente pelo governo imperial japonês durante a II Guerra como argumento favorável a uma zona de coprosperidade. Ver Kasahara (2004).

11 É esta sequência de curvas de um determinado produto ao longo do tempo que formaria graficamente o voo articulado dos gansos.

12 Há diversas versões do EGV, a desenvolvida por Kojima (2000), baseada na teoria de HeckscherOhlim e dinamizada pelos fluxos de investimento direto (IDE) supõe uma complementaridade acordada e harmoniosa. 
vantagens comparativas, sendo as grandes firmas "condutoras benevolentes" do progresso tecnológico (KASAHARA, 2004). O crescimento é causado pelos ganhos de produtividade decorrentes de uma maior eficiência alocativa e eficiência produtiva (suposta na utilização de tecnologia mais avançada). ${ }^{13}$

Há cinco críticas principais ao EGV como descrição de um desenvolvimento regional articulado. As três primeiras aplicam-se inteiramente à formulação de Kojima (2000). Sua versão supõe uma harmonia de interesses entre os países, automatismo do progresso técnico e não incorpora fatores de demanda. Estas críticas, entretanto, não necessariamente se aplicam à formulação original.

De fato, no esquema original de Akamatsu (1962), na fase de homogeneização, a concorrência entre os produtores locais e as importações do país mais avançado possui custos e a passagem desta etapa à produção local pode ser lenta e resultar em desemprego ( ROWTHORN, 1996). Embora seja uma possibilidade, não é intrínseca à formulação de uma "importação reversa", sobre a qual o protecionismo aumentaria os potenciais conflitos.

Em relação ao progresso tecnológico, como sugerem Ginzburg e Simonazzi (2003), o EGV descreve uma hierarquia nas especializações nacionais cujo deslocamento e resultado depende de circunstâncias não automáticas. Na formulação originária de Akamatsu (1962), havia explicitamente espaço para a intervenção do governo. Numa formulação contemporânea, essas envolveriam o desenho de políticas visando a inovação, cópia de técnicas e adaptação tecnológica.

A inexistência de fatores automáticos pode propiciar uma inserção na rede da produção fragmentada orientada por critérios exclusivamente centrados na busca de uma maior eficiência alocativa. Esta forma de inserção resultaria num baixo dinamismo tecnológico e menores potencialidades para o desenvolvimento dos países mais atrasados. ${ }^{14}$

Ambas as críticas apontariam para a necessidade de incorporar no esquema de divisão intrarregional do trabalho novos motores externos às firmas multinacionais. A introdução de fatores de demanda, como desenvolvido em Medeiros (1997) é, por sua vez, plenamente possível

13 Nesta formulação é a iniciativa do ganso líder (o país mais avançado) que inaugura uma pressão para baixo nos demais países iniciando a sequência articulada. Este sentido de cima para baixo e não de baixo para cima é distinta da formulação original de Akamatsu que considerava que a estratégia de imitação do país seguidor punha em marcha o processo.

Em torno deste aspecto há uma notável diferença entre os países do Asean 4 (Filipinas, Indonésia Malásia, Tailândia) os países com maior agressividade tecnológica como Coreia, Taiwan e China. 
de se incorporar no EGV e é crucial para o entendimento dos estímulos macroeconômicos ao crescimento regional. ${ }^{15}$

As outras duas críticas baseiam-se na ascensão chinesa e na afirmação da fragmentação produtiva como um novo paradigma. Argumenta-se que a divisão de trabalho por atividades produtivas e não por setores tal como vem se afirmando nos anos mais recentes e a grande ascensão da China no comércio internacional teria diluído a capacidade explicativa do EGV. Consideremos brevemente estas críticas e a plausibilidade do EGV para o exame do padrão de desenvolvimento regional asiático que se afirmou nas duas últimas décadas do século XX.

\subsection{A Triangulação Comercial no Leste Asiático}

O longo período de valorização do iene em relação ao dólar entre 1985 e 1995 inaugurou uma época de intenso laço comercial entre os principais países do leste asiático, após um prolongado distanciamento motivado por razões geopolíticas desde a Segunda Guerra Mundial. Aos novos custos de produção e sob intensa pressão comercial americana contra as práticas comerciais do Japão, parcela importante da produção industrial japonesa deixava de ser competitiva no mercado americano (o principal mercado para as exportações japonesas) e, de resto, para as exportações dos países do Sudeste Asiático. Ao lado de deslocamentos de processos produtivos completos para países asiáticos de menores custos, isto é, custos unitários de trabalho em dólar inferiores aos japoneses, as grandes empresas nipônicas (e posteriormente pequena e médias empresas também) deslocaram para estes países segmentos padronizados de processo produtivos, estabelecendo uma divisão vertical de trabalho em que peças, componentes e bens de capital fornecidos a partir do Japão eram montados em outros países da região (por filiais japonesas ou por firmas locais) e o produto final era exportado para os EUA e demais mercados ocidentais. Formava-se assim uma triangulação e um esquema de produção compartilhada e de divisão de trabalho, envolvendo diversas economias asiáticas.

Tendo em vista o fato de que o leste e sudeste asiáticos possuem uma diversidade grande de economias segundo o grau de desenvolvimento relativo, formou-se uma especialização vertical. De um lado o Japão, de outro, a primeira geração de tigres asiáticos formada por Coreia, Taiwan, Hong Kong e Cingapura, e além de alguns países do sudeste asiático como Tailândia, Malásia, Indonésia e Filipinas (Asean-4) e, com uma

15 Em Medeiros (1997) explica-se o desenvolvimento regional do Leste Asiático incorporando os fatores de demanda ao EGV, enfatizando, em particular, o papel dos EUA como consumidor final. 
dinâmica especial, a China continental. A diversidade asiática decorria não apenas dos distintos graus de industrialização e tamanhos relativos das economias, mas da formação na região de sofisticados centros comerciais e financeiros de longa tradição em cidades-Estados, como Hong Kong e Cingapura, ao lado de economias tecnologicamente avançadas, como o Japão, Coreia e Taiwan, e economias com abundantes reservas de mão de obra barata e disciplinada, como especialmente a China.

\subsection{A Ascensão Chinesa, a Triangulação Comercial e a Formação de um Novo Polo}

A valorização do iene a partir de 1995 e a contração abrupta dos IDE japoneses vinculados às exportações asiáticas para terceiros mercados (principalmente os EUA) ocasionou uma forte instabilidade na dinâmica regional. Como estes países possuíam regimes cambiais vinculados ao dólar, a valorização desta moeda em relação ao iene levou a uma valorização real das principais moedas asiáticas, com a exceção do yuan chinês que passara em 1994 por desvalorização. A maior pressão competitiva do Japão em segmentos de maior valor unitário da indústria eletrônica (aumentando a concorrência com a Coreia), a queda do preço dos semicondutores e a afirmação da competitividade da China em manufaturas e segmentos de tecnologia de informação (TI) deslocaram as exportações da Asean nos mercados mundiais, em particular nos EUA (devido ao novo alinhamento cambial) e no Japão devido à recessão que se afirmou na segunda metade dos anos 90.

A reação chinesa à crise asiática de 1997 foi o prosseguimento do alto crescimento a partir de um programa de obras públicas e manutenção da estabilidade do yuan indexado ao dólar (McKINNON; SCNA$\mathrm{BL}, 2003)$. Esta decisão introduziu mudanças no padrão de crescimento chinês e na dinâmica regional sem, entretanto, desfazer a triangulação do comércio regional descrita anteriormente. De um lado, investimentos japoneses, mas sobretudo de Hong Kong e de Taiwan (e numa proporção menor, investimentos ocidentais) começaram, desde a segunda metade dos 1990, a deslocar para a China o centro manufatureiro e exportador asiático. Por outro lado, redes de comércio varejista como Walmart e firmas virtuais como a Nike, estabeleceram na China seu principal centro produtor. Numa outra direção, uma nova onda de IDE voltada agora para o mercado interno (market seeking) concentrou-se na China. A elevação do poder de consumo urbano na China e a aceleração dos investimentos internos tornaram o mercado interno chinês um novo atrator do mercado mundial e regional. Como resultado, a 
China afirmou-se como um duplo polo na economia mundial: de um lado, tornou-se o principal produtor e exportador asiático de produtos finais intensivos em mão de obra (tanto em bens de consumo quanto em máquinas da TI), de outro se afirmou como grande mercado para peças e componentes, bens intermediários e bens de capitais (MEDEIROS, 2006). Uma consequência da afirmação deste duplo polo na região asiática foi a relocalização do déficit que os EUA possuíam com a Ásia para a China.

O Japão afirmou-se como o principal fornecedor de partes e componentes montados na China e exportados para os EUA, mas tanto a Coreia quanto Taiwan, bem como as firmas localizadas em Hong Kong beneficiaram-se desta especialização. Se em 1990 o Japão destinava apenas 2,1\% de suas exportações para a China, em 2007, a China absorvia 15,3\% das exportações japonesas (Quadro 1). O mesmo ocorreu com a Coreia do Sul e Taiwan. A integração produtiva e a especialização vertical foi o principal veículo desta expansão da corrente de comércio como pode ser observado no Quadro 2.

\begin{tabular}{|c|c|c|c|c|c|c|c|}
\hline Exportações & & L. Asiático & Tigres & ASEAN 4 & Japão & China & EUA \\
\hline \multirow{3}{*}{ Japão } & 1990 & 29,7 & 19,7 & 7,7 & $\mathrm{x}$ & 2,1 & 31,7 \\
\hline & 2000 & 40,2 & 23,9 & 9,5 & $\mathrm{x}$ & 6,3 & 30,0 \\
\hline & 2007 & 46,8 & 22,4 & 8,3 & $\mathrm{x}$ & 15,3 & 20,4 \\
\hline \multirow{3}{*}{ China } & 1990 & 66,2 & 48,6 & 2,8 & 14,5 & $\mathrm{x}$ & 8,3 \\
\hline & 2000 & 48,1 & 26,7 & 3,7 & 16,7 & $\mathrm{x}$ & 20,9 \\
\hline & 2007 & 37,8 & 24,1 & 4,1 & 8,4 & $\mathrm{x}$ & 19,1 \\
\hline \multirow{3}{*}{ Hong Kong } & 1990 & 44,4 & 9,8 & 4,0 & 5,7 & 24,7 & 24,1 \\
\hline & 2000 & 50,5 & 6,8 & 3,3 & 5,5 & 34,5 & 23,2 \\
\hline & 2007 & 62,9 & 6,0 & 3,4 & 4,4 & 48,3 & 13,5 \\
\hline \multirow{3}{*}{ Taiwan } & 1990 & 37,0 & 17,8 & 6,8 & 12,4 & 0,0 & 32,5 \\
\hline & 2000 & 48,8 & 27,4 & 7,3 & 11,1 & 2,8 & 23,4 \\
\hline & 2007 & 64,8 & 22,8 & 7,4 & 6,4 & 25,3 & 13,0 \\
\hline \multirow{3}{*}{ Coreia do Sul } & 1990 & 35,2 & 8,6 & 5,0 & 19,4 & 2,1 & 29,9 \\
\hline & 2000 & 45,2 & 14,2 & 7,2 & 11,9 & 10,7 & 21,9 \\
\hline & 2007 & 48,1 & 11,7 & 5,5 & 7,1 & 22,1 & 12,4 \\
\hline \multirow{3}{*}{ Cingapura } & 1990 & 46,3 & 13,6 & 21,0 & 8,7 & 1,5 & 21,3 \\
\hline & 2000 & 56,2 & 17,4 & 24,9 & 7,5 & 3,9 & 17,3 \\
\hline & 2007 & 63,3 & 17,1 & 28,9 & 4,8 & 9,7 & 8,9 \\
\hline
\end{tabular}


(continuação)

\begin{tabular}{|l|l|l|l|l|l|l|l|}
\hline \multirow{4}{*}{ Tailândia } & $\mathbf{1 9 9 0}$ & 38,1 & 15,2 & 3,9 & 17,2 & 1,2 & 22,7 \\
\cline { 2 - 8 } & $\mathbf{2 0 0 0}$ & 48,5 & 19,1 & 7,6 & 14,7 & 4,1 & 21,4 \\
\cline { 2 - 8 } & $\mathbf{2 0 0 7}$ & 52,7 & 16,0 & 10,2 & 11,8 & 9,7 & 12,6 \\
\hline \multirow{4}{*}{ Malásia } & $\mathbf{1 9 9 0}$ & 57,1 & 32,7 & 6,0 & 15,8 & 2,1 & 16,9 \\
\cline { 2 - 8 } & $\mathbf{2 0 0 0}$ & 54,3 & 30,0 & 7,1 & 13,1 & 3,1 & 20,5 \\
\cline { 2 - 8 } & $\mathbf{2 0 0 7}$ & 54,7 & 25,8 & 9,3 & 9,1 & 8,8 & 15,6 \\
\hline \multirow{4}{*}{ Filipinas } & $\mathbf{1 9 9 0}$ & 37,2 & 12,3 & 4,2 & 19,8 & 0,8 & 37,9 \\
\cline { 2 - 8 } & $\mathbf{2 0 0 0}$ & 47,8 & 23,8 & 7,3 & 14,7 & 1,7 & 30,0 \\
\cline { 2 - 8 } & $\mathbf{2 0 0 7}$ & 60,7 & 25,2 & 8,8 & 14,5 & 11,4 & 17,0 \\
\hline \multirow{4}{*}{ Indonésia } & $\mathbf{1 9 9 0}$ & 66,8 & 18,5 & 2,3 & 42,5 & 3,2 & 13,1 \\
\cline { 2 - 8 } & $\mathbf{2 0 0 0}$ & 58,5 & 23,8 & 6,1 & 23,2 & 4,5 & 13,7 \\
\cline { 2 - 8 } & $\mathbf{2 0 0 7}$ & 59,1 & 19,6 & 8,8 & 20,7 & 8,5 & 10,2 \\
\hline
\end{tabular}

Quadro 1 - Destino das Exportações Asiáticas (em \% do total)

Fonte: Elaborado por Isabela Nogueira a partir de UN Comtrade e Bureau of Foreign Trade (para os dados de Taiwan).

Nota: Leste Asiático: Asean 10 (Malásia, Tailândia, Indonésia, Filipinas, Vietnã, Brunei, Myamar, Cingapura, Camboja, Laos) China, Japão, Hong Kong, Coreia do Sul e Taiwan.

\begin{tabular}{|c|c|c|c|c|c|c|c|c|c|c|}
\hline Exportações & & China & $\begin{array}{l}\text { Hong } \\
\text { Kong }\end{array}$ & Coreia & Cingapura & ASEAN 4 & Japão & Ásia & EUA & Mundo \\
\hline \multirow{5}{*}{1998} & \multirow{5}{*}{$\begin{array}{l}\text { FC } \\
\text { FCA } \\
\text { IMPC } \\
\text { IMSF } \\
\text { P }\end{array}$} & 47,3 & 37,2 & 18,2 & 10,1 & 21,2 & 17,6 & 25,3 & 14,8 & 24,7 \\
\hline & & 14,7 & 12,5 & 18,2 & 27,2 & 11,5 & 25,9 & 18,9 & 23,8 & 17,8 \\
\hline & & 10,4 & 19,6 & 25,2 & 39,7 & 33,0 & 31,2 & 26,2 & 29,7 & 20,5 \\
\hline & & 22,9 & 22,7 & 36,1 & 13,8 & 22,2 & 21,5 & 23,8 & 22,1 & 26,5 \\
\hline & & 4,3 & 1,7 & 0,7 & 0,8 & 7,4 & 0,4 & 2,6 & 5,4 & 6,7 \\
\hline \multirow{5}{*}{2001} & \multirow{5}{*}{$\begin{array}{l}\text { FC } \\
\text { FCA } \\
\text { IMPC } \\
\text { IMSF } \\
\text { P } \\
\end{array}$} & 41,3 & 33,6 & 18,0 & 7,9 & 19,8 & 17,5 & 24,0 & 15,2 & 23,6 \\
\hline & & 18,3 & 14,2 & 22,3 & 22,5 & 13,7 & 23,9 & 19,4 & 22,1 & 17,2 \\
\hline & & 14,9 & 26,2 & 24,1 & 45,3 & 33,7 & 31,5 & 28,0 & 30,3 & 20,4 \\
\hline & & 20,6 & 24,4 & 28,7 & 14,1 & 22,2 & 22,0 & 22,3 & 22,7 & 24,6 \\
\hline & & 3,8 & 1,5 & 0,4 & 0,6 & 7,7 & 0,6 & 2,6 & 5,0 & 9,3 \\
\hline \multirow{5}{*}{2004} & \multirow{5}{*}{\begin{tabular}{|l} 
FC \\
FCA \\
IMPC \\
IMSF \\
P
\end{tabular}} & 32,7 & 25,8 & 15,4 & 6,8 & 16,6 & 16,4 & 21,1 & 15,5 & 23,7 \\
\hline & & 25,3 & 13,8 & 23,2 & 17,8 & 13,4 & 23,3 & 20,8 & 20,8 & 17,1 \\
\hline & & 18,2 & 35,1 & 29,2 & 47,1 & 25,5 & 31,4 & 28,8 & 27,9 & 20,4 \\
\hline & & 20,8 & 23,6 & 27,0 & 17,1 & 23,6 & 23,4 & 22,8 & 24,6 & 26,1 \\
\hline & & 2,1 & 1,5 & 0,4 & 0,6 & 8,8 & 0,8 & 2,4 & 6,1 & 7,6 \\
\hline
\end{tabular}


(continuação)

\begin{tabular}{|l|l|l|l|l|l|l|l|l|l|l|}
\hline & FC & 29,6 & 26,0 & 14,0 & 8,6 & 15,6 & 20,9 & 20,6 & 16,2 & $\mathrm{Nd}$ \\
\cline { 3 - 11 } 2007 & FCA & 27,9 & 15,5 & 27,5 & 12,8 & 13,3 & 21,5 & 18,8 & 21,4 & $\mathrm{Nd}$ \\
\cline { 3 - 11 } & IMPC & 17,3 & 37,2 & 26,4 & 42,7 & 21,4 & 27,7 & 21,5 & 23,9 & $\mathrm{Nd}$ \\
\cline { 3 - 11 } & IMSF & 22,9 & 19,5 & 25,2 & 15,7 & 27,6 & 22,8 & 22,8 & 25,2 & $\mathrm{Nd}$ \\
\cline { 3 - 11 } & $\mathbf{P}$ & 1,1 & 1,5 & 0,5 & 0,7 & 10,4 & 1,0 & 9,1 & 7,4 & $\mathrm{Nd}$ \\
\hline
\end{tabular}

Quadro 2 - Padrão de Comércio Asiático Segundo Categoria de Bens (em \% do Total, Exportações)

Fonte: Elaborado por Isabela Nogueira a partir de UN Comtrade (para 2007) e de Aminian, Fung e lizaka (2007) para os demais anos.

Nota: Metodologia de agregação utilizada por Aminian, Fung e lizaka (2007) com base no sistema de classificação de produtos BEC (Broad Economic Categories) divulgado pela UN Comtrade. FC: Bens Finais de Consumo, FCA: Bens Finais de Capital, IMPC: Bens Intermediários (Partes e Componentes), IMPSF: Bens Intermediários (Semifinais), P: Bens Primários.

Assim, direta e indiretamente, o crescimento chinês teve efeitos positivos sobre as exportações dos países de menor desenvolvimento do Asean-4, tanto em bens finais quanto em bens intermediários. Consequentemente, a China passou a ter um fluxo de importações muito mais concentrado na Ásia - sobretudo em máquinas e peças e componentes - do que suas exportações - especialmente voltadas para os EUA e EU. ${ }^{16}$

Portanto, o efeito final do crescimento chinês sobre a região decorreu não apenas do maior ou menor grau de complementaridade da rede verticalizada de produção e do processamento das suas exportações, mas da taxa de crescimento do seu mercado interno.

O dinamismo do comércio asiático revela que a questão central para a maior estabilidade do crescimento em economias abertas e da sua corrente de comércio depende essencialmente da manutenção da solvência externa das economias, situação que por sua vez depende dos regimes macroeconômicos e da forma de agir do centro cíclico regional.

\subsection{A Ascensão Chinesa e o Esquema dos Gansos Voadores}

Até que ponto esta nova dinâmica mudou essencialmente o EGV descrito anteriormente?

A crítica atualmente mais persistente ao EGV é a sua inadequação

16 Estatísticas provenientes dos demais países asiáticos apresentam, entretanto, um déficit com a China (Quadro 5). As imprecisões no registro do comércio entre a China e Hong Kong possivelmente explicam parte desta grande discrepância. Independente do saldo comercial, que, diga-se, é positivo para cada país asiático com os EUA (que se mantêm como consumidor final de cada país e da região asiática) a expansão chinesa tornou-se o principal mercado de expansão para as demais economias asiáticas. 
às tendências mais recentes, devido ao predomínio da especialização vertical no comércio intrarregional e não mais a especialização e o comércio em produtos (especialização horizontal), tal como descrito nas formulações usuais do esquema baseadas na identificação da produção de um produto com um dado estágio de desenvolvimento. Alguns estudos como o de Tung (2003), que seguem uma interpretação do EGV como um "ciclo de produto inter-industrial", evidenciam que as vantagens competitivas reveladas sobre semicondutores e partes e componentes não mais endossariam uma ordenação hierárquica como a prevista pelo EGV a partir de $1995 .{ }^{17} \mathrm{Tal}$ mudança teria sido afirmada pela ascensão chinesa, pelo seu catch-up tecnológico e seu modelo industrial baseado na modularização e padronização. A questão mais geral seria a redefinição das vantagens competitivas associada não a bens, mas a determinados estágios de produção. A intensa importação chinesa de partes e componentes do Japão e dos Tigres Asiáticos teria alterado o antigo esquema e evidenciado uma nova realidade.

Esta foi a interpretação do White Paper on International Trade do Ministério da Economia, Comércio e Indústria (Meci) do Japão, publicado em 2001. Argumenta-se neste documento que a China, a partir dos amplos fluxos de IDE teria dado um salto na tecnologia da informação (TI) alterando a sua posição na estrutura sequencial do Japão, os Tigres e o Asean-4. Com a rápida ascensão chinesa, a complementaridade teria dado lugar a uma pesada concorrência entre a China e os países asiáticos.

Entretanto, em relação ao conteúdo tecnológico das exportações, diversos estudos empíricos contestam estes resultados. O estudo sobre vantagens comparativas reveladas na indústria eletrônica na Ásia de Ginzburg e Simonazzi (2003) mostra o predomínio de uma estrutura de especialização muito próxima a que seria descrita pelo EGV ${ }^{18} \mathrm{Kwan}$ (2002), comparou a evolução das exportações industriais dos países asiáticos usando um indicador de sofisticação das exportações ${ }^{19}$ (usando dez dígitos do sistema de harmonização internacional, HS) para os EUA, entre os anos 1990, 1995 e 2000. O resultado encontrado vai exatamente

17 A vantagem comparativa revelada de um país na exportação de um determinado bem indica a importância relativa deste bem nas exportações do país em relação a importância deste produto nas exportações mundiais (TUNG, 2003).

18 A principal diferença com o estudo de Tung é a adoção da área como bloco de referencia para o cálculo da especialização do país e a inclusão dos EUA na área de comércio asiática e uma agregação distinta da indústria eletrônica.

19 A hipótese básica é a de que países de renda alta exportam produtos de alto valor adicionado, assim é possível construir um índice de sofisticação de um bem como uma média ponderada da renda per capita dos países exportadores usando como ponderação suas participações na exportação mundial e é também possível calcular um índice de sofisticação de um país, considerando que quanto maior é o percentual de suas exportações em produtos de maior valor adicionado, mais sofisticada é a sua pauta exportadora. Ver Kwan, 2002. 
ao encontro do previsto no EGV. Embora todos os países tenham elevado o seu grau de sofisticação, a hierarquia não mudou, as exportações mais sofisticadas originam-se do Japão, seguido dos Tigres Asiáticos, dos países do Asean-4 e finalmente da China.

Em relação ao tipo de comércio entre Japão e China, as evidências apontam para uma alta complementaridade - com o Japão concentrando-se em atividades de maior valor adicionado (em partes e componentes e também produtos finais, como televisões de alta definição) e a China em atividades intensivas em trabalho com alto conteúdo importado e em produtos de menor valor adicionado. Esta mesma divisão se estabelece com Coreia e Taiwan. Os grandes passos realizados na China na TI deslocam progressivamente sua especialização na direção de bens de capital, mas ainda não resultaram, de acordo com as evidências destes trabalhos, num deslocamento na sua posição hierárquica, centrada na produção de bens de menor valor unitário e em estágios produtivos da indústria eletrônica caracterizados por atividades padronizadas e intensivas em trabalho.

Esta inserção externa, entretanto, começou a mudar. Com efeito, a agressiva política de absorção da tecnologia advinda das empresas estrangeiras em parcerias com empresas chinesas constitui, junto com o esforço classicamente japonês e coreano de formação de "campeões nacionais" verticalmente integrados, uma característica distintiva da China que não caracteriza uma inserção passiva na cadeia de valor adicionado, típica do processamento de exportações. Embora globalmente ainda seja modesto, é notável o fato de que o esforço de PËD na China, que é mais intenso nas empresas estatais e nas empresas coletivas (SUN, 2002).

Em síntese, deve-se observar que a integração produtiva asiática foi o resultado de múltiplos processos. A alternância entre complementaridade e rivalidade, os deslocamentos sequenciais de especialização produtiva e a existência de um grande consumidor final e importador líquido das manufaturas asiáticas possibilitaram a formação de um ambiente econômico favorável a uma elevada taxa de crescimento econômico liderada pela acumulação de capital industrial. Políticas macroeconômicas e industriais criaram os incentivos para decisões privadas de investimento na montagem de uma rede produtiva integrada.

É importante observar que, por razões geopolíticas, apenas com muito atraso a integração asiática passou a contar com mecanismos institucionais construídos pelos governos asiáticos. ${ }^{20}$

20 "Until the end of the 1990s, China was not a member of any regional free trade or economic cooperation arrangement except the Asia- Pacific Economic Cooperation (Apec) forum, nor did it have any bilateral free trade or investment agreement. Thus the Chinese proposal for a free 


\section{A Integração Produtiva e o Mercosul}

Devido à sua clássica especialização produtiva centrada na exportação de commodities e baixo grau de industrialização (ainda que com ampla diferenciação regional), os países da América do Sul não acompanharam, nas duas últimas décadas, o crescimento das exportações mundiais, em que pese a expansão recente dos preços das commodities.

Historicamente, ainda que a integração econômica na América do Sul fosse reiteradamente reconhecida como uma necessidade para uma maior racionalização ao processo de substituição de importações e promoção de exportações (PREBISCH,1959), a precária inserção externa das economias e a instabilidade macroeconômica dela decorrente impediram sua evolução. A escassez de divisas (dólares) nos anos sessenta, acompanhada pelo fracasso da industrialização na maioria dos países do continente e o boom do endividamento externo dos anos setenta, afastaram qualquer projeto de regionalização de maior fôlego.

A crise da dívida dos anos oitenta, com a sua sequela de alta inflação e fuga de capitais particularmente intensa em países como a Argentina e o Brasil, tornava remota a afirmação de um projeto regional. Entretanto, por iniciativa política dos governos Sarney (Brasil) e Alfonsin (Argentina), em meio a uma década de crise econômica e política, estabeleceu-se o Mercosul, o Mercado Comum do Sul. Em seu desenho inicial, objetivavase estimular o desenvolvimento industrial com a criação de um mercado comum mais amplo. Em 1991, no Tratado de Assunção, estes dois países assinaram com o Paraguai e o Uruguai um acordo visando à formação de um mercado comum. Esta iniciativa se deu, entretanto, em meio a uma radical guinada na política comercial e industrial da Argentina e do Brasil favorável ao livre-comércio, desregulação, abertura aos fluxos de capitais e privatização.

Tendo em vista a debilidade dos mercados externos globais ao longo dos 1990 para a região, a formação de uma união aduaneira na América do Sul - com a redução da maioria das tarifas intrabloco e com a adoção de uma tarifa externa comum -, promoveu uma rápida expansão da corrente de comércio entre os países (e tendo em vista a estagnação dos mercados externos gerou um elevado índice de comércio regional) com particular destaque para a indústria automobilística e, nos anos mais recentes, um significativo crescimento do investimento direto oriundo dos países do bloco. Contudo, e ao contrário do que se estabeleceu na Ásia, a maior debilidade de mecanismos estruturais indutores e as características

trade area with the Asean in November 2000 marked a policy shift by its government to embark on regionalism as a complement to its global external economic relations" (UNCTAD, 2007, p. 91). 
macroeconômicas prevalecentes limitaram as possibilidades para uma integração econômica maior, tornando o Mercosul uma união aduaneira "incompleta e imperfeita" (CHUDNOVSKY; FANELLI, 2001), em que as necessidades impostas pelas crises externas tiveram precedência sobre os arranjos de longo prazo voltados à consolidação do bloco.

Com efeito, a evolução do comércio entre a Argentina e o Brasil foi fortemente influenciada pela evolução da taxa real de câmbio e pela frágil inserção financeira internacional. Mudanças súbitas nos fluxos externos, como a que levou ao colapso da moeda brasileira em 1999, resultaram numa contração substancial das exportações argentinas para o Brasil, provocando uma ampliação da fragilidade do balanço de pagamentos da Argentina. A concessão de amplos subsídios subnacionais para a relocalização da indústria automobilística no Brasil, bem como a desvalorização do câmbio, impactaram fortemente a Argentina e a própria sustentação do bloco. Por sua vez, a crise cambial argentina de 2001 levou à introdução de modificações dos acordos estabelecidos no Mercosul, com a elevação da tarifa sobre os bens de consumo e redução substancial das importações de bens de capital e produtos de tecnologia de informação para os países de fora do bloco. Estas mudanças, ainda que defendidas como medidas temporárias, iniciaram a discussão sobre a conveniência de transformar a união aduaneira do Mercosul num simples acordo de livre-comércio, liberando os países para praticar as tarifas que desejassem aos países de fora do bloco.

Como resultado desta crônica volatilidade macroeconômica, mas também do efeito das mudanças nos termos de troca ocorrida nos últimos anos, o peso do comércio intrarregional hoje no comércio total da região oscila em torno de 15\%, inferior ao que havia nos anos 90 (UNCTAD, 2007). Ademais, este peso é muito desigual entre os países, sendo muito inferior no Brasil (10\%) em relação aos demais países do bloco. O boom exportador da América do Sul foi essencialmente centrado nas commodities destinadas aos mercados globais. Os Quadros 3 e 4 contrastam as condições macroeconomicamente distintas da regionalização asiática e sul-americana. O Quadro 5 apresenta a evolução do comercio regional sul-americano. 
Leste Asiático

\begin{tabular}{|l|l|l|l|l|l|l|}
\hline & $\mathbf{1 9 9 0}$ & $\mathbf{1 9 9 5}$ & $\mathbf{1 9 9 7}$ & $\mathbf{2 0 0 0}$ & $\mathbf{2 0 0 5}$ & $\mathbf{2 0 0 7}$ \\
\hline Japão & 43,943 & 111,40 & 96,553 & 119,605 & 165,69 & 212,82 \\
\hline China & 11,997 & 1,62 & 36,962 & 20,519 & 160,82 & 360,71 \\
\hline Coreia do Sul & $-2,014$ & $-8,67$ & $-8,287$ & 12,251 & 14,98 & 5,95 \\
\hline Hong Kong & 4,764 & $-9,06$ & $-7,729$ & 6,994 & 20,23 & 25,46 \\
\hline Taiwan & 10,923 & 5,47 & 7,05 & 8,899 & 16,02 & 31,70 \\
\hline Cingapura & 3,122 & 14,39 & 14,874 & 10,717 & 22,28 & 39,16 \\
\hline Indonésia & $-3,2$ & $-6,80$ & $-3,8$ & 7,988 & 0,28 & 11,01 \\
\hline Malásia & $-0,918$ & $-8,64$ & $-5,935$ & 8,487 & 19,99 & 26,05 \\
\hline Filipinas & $-2,69$ & $-1,97$ & $-4,33$ & $-2,225$ & 1,98 & 6,35 \\
\hline Tailândia & $-7,137$ & $-13,23$ & $-3,11$ & 9,328 & $-7,64$ & 14,92 \\
\hline \multicolumn{7}{|l|}{$\mathbf{M e r c o s u l}$} \\
\hline
\end{tabular}

Quadro 3 - Saldo em Transações Correntes (US\$ bilhões) no Leste Asiático e no Mercosul

Fonte: Elaborado por Isabela Nogueira a partir de IMF Data and Statistics.

\begin{tabular}{|l|l|l|l|l|l|l|}
\hline & $\mathbf{1 9 9 5}$ & $\mathbf{1 9 9 7}$ & $\mathbf{2 0 0 0}$ & $\mathbf{2 0 0 5}$ & $\mathbf{2 0 0 7}$ & Desvio padrão \\
\hline Japão & 107,02 & 84,45 & 99,99 & 79,14 & 65,64 & 16,54 \\
\hline China & 82,35 & 98,32 & 99,99 & 91,39 & 96,69 & 7,14 \\
\hline Coreia do Sul & 112,24 & 106,64 & 100,00 & 112,54 & 119,46 & 7,28 \\
\hline Hong Kong & 86,33 & 102,06 & 100,00 & 79,91 & 75,12 & 11,97 \\
\hline Taiwan & 102,43 & 103,36 & 100,00 & 87,82 & 80,17 & 10,26 \\
\hline Indonésia & 147,82 & 147,50 & 100,00 & 114,76 & 113,65 & 21,71 \\
\hline Malásia & 118,70 & 121,52 & 99,99 & 95,29 & 101,46 & 11,87 \\
\hline Filipinas & 112,99 & 121,66 & 100,00 & 90,06 & 109,28 & 12,16 \\
\hline Tailândia & 118,56 & 117,83 & 99,99 & 97,02 & 111,54 & 10,01 \\
\hline Argentina & 87,47 & 88,83 & 100,00 & 45,86 & 44,46 & 26,17 \\
\hline Brasil & 130,88 & 142,20 & 99,99 & 98,37 & 119,91 & 19,13 \\
\hline
\end{tabular}

Quadro 4 - Taxa Real de Cambio (média do ano, 2000=100) e seu Desvio Padrão em alguns Países Asiáticos e Sul-Americanos

Fonte: Elaborado por Isabela Nogueira a partir de BIS Statistics. 


\begin{tabular}{|c|c|c|c|c|c|c|c|c|}
\hline Exportações & & Mercosul & Brasil & Argentina & Paraguai & Uruguai & Venezuela* & EUA \\
\hline & 1990 & 4,2 & $\mathrm{x}$ & 2,1 & 1,2 & 0,9 & 0,9 & 24,6 \\
\hline \multirow[t]{3}{*}{ Brasil } & 2000 & 14,0 & $\mathrm{x}$ & 11,3 & 1,5 & 1,2 & 1,4 & 24,3 \\
\hline & 2007 & 10,8 & $\mathrm{x}$ & 9,0 & 1,0 & 0,8 & 2,9 & 15,8 \\
\hline & 1990 & 14,8 & 11,5 & $\mathrm{x}$ & 1,2 & 2,1 & 1,2 & 13,8 \\
\hline \multirow[t]{3}{*}{ Argentina } & 2000 & 31,9 & 26,5 & $\mathrm{x}$ & 2,3 & 3,1 & 0,8 & 12,0 \\
\hline & 2007 & 22,4 & 18,8 & $\mathrm{x}$ & 1,4 & 2,2 & 2,1 & 7,8 \\
\hline & 1990 & 39,6 & 32,6 & 5,8 & $\mathrm{x}$ & 1,2 & 0,6 & 4,3 \\
\hline \multirow[t]{3}{*}{ Paraguai } & 2000 & 63,5 & 38,6 & 10,7 & $\mathrm{x}$ & 14,1 & 1,1 & 3,9 \\
\hline & 2007 & 49,3 & 20,0 & 19,8 & $\mathrm{x}$ & 9,5 & 3,1 & 2,6 \\
\hline & 1990 & 34,8 & 29,6 & 4,8 & 0,4 & $\mathrm{x}$ & 0,1 & 9,4 \\
\hline \multirow[t]{3}{*}{ Uruguai } & 2000 & 44,5 & 23,1 & 17,9 & 3,6 & $\mathrm{x}$ & 0,7 & 8,4 \\
\hline & 2007 & 27,7 & 16,2 & 9,8 & 1,7 & $\mathrm{x}$ & 2,2 & 11,2 \\
\hline & 1990 & 2,0 & 1,9 & 0,0 & 0,0 & 0,0 & $\mathrm{x}$ & 51,6 \\
\hline \multirow[t]{2}{*}{ Venezuela } & 2000 & 4,2 & 3,6 & 0,1 & 0,0 & 0,5 & $\mathrm{x}$ & 59,6 \\
\hline & 2007 & 2,5 & 2,4 & 0,0 & 0,0 & 0,0 & $\mathrm{x}$ & 48,8 \\
\hline \multirow[t]{2}{*}{ Importações } & & Mercosul & Brasil & Argentina & Paraguai & Uruguai & Venezuela* & EUA \\
\hline & 1990 & 10,9 & $\mathrm{x}$ & 6,7 & 1,5 & 2,6 & 1,8 & 20,1 \\
\hline \multirow[t]{3}{*}{ Brasil } & 2000 & 14,2 & $\mathrm{x}$ & 12,3 & 0,6 & 1,1 & 2,4 & 23,3 \\
\hline & 2007 & 9,7 & $\mathrm{x}$ & 8,6 & 0,4 & 0,7 & 0,3 & 15,7 \\
\hline & 1990 & 20,4 & 17,5 & $\mathrm{x}$ & 1,0 & 1,9 & 0,2 & 20,1 \\
\hline \multirow[t]{3}{*}{ Argentina } & 2000 & 28,5 & 25,6 & $\mathrm{x}$ & 1,2 & 1,7 & 0,1 & 18,9 \\
\hline & 2007 & 36,2 & 32,8 & $\mathrm{x}$ & 2,4 & 1,0 & 0,1 & 11,9 \\
\hline & 1990 & 30,0 & 16,5 & 12,8 & $\mathrm{x}$ & 0,7 & 0,1 & 12,7 \\
\hline \multirow[t]{3}{*}{ Paraguai } & 2000 & 51,6 & 24,5 & 23,3 & $\mathrm{x}$ & 3,7 & 0,1 & 7,3 \\
\hline & 2007 & 44,7 & 29,0 & 14,4 & $\mathrm{x}$ & 1,3 & 2,6 & 5,0 \\
\hline & 1990 & 39,6 & 23,3 & 15,5 & 0,8 & $\mathrm{x}$ & 0,5 & 9,9 \\
\hline \multirow[t]{3}{*}{ Uruguai } & 2000 & 43,8 & 19,2 & 24,1 & 0,4 & $\mathrm{x}$ & 4,3 & 9,8 \\
\hline & 2007 & 45,8 & 23,2 & 22,1 & 0,5 & $\mathrm{x}$ & 11,4 & 7,4 \\
\hline & 1990 & 5,9 & 4,0 & 1,9 & 0,0 & 0,0 & $\mathrm{x}$ & 46,7 \\
\hline \multirow[t]{2}{*}{ Venezuela } & 2000 & 7,1 & 5,0 & 1,6 & 0,2 & 0,3 & $\mathrm{x}$ & 37,8 \\
\hline & 2007 & 10,1 & 8,0 & 1,7 & 0,2 & 0,2 & $\mathrm{x}$ & 24,2 \\
\hline
\end{tabular}

Quadro 5 - Destino das Exportações e Origem das Importações dos Países - Mercosul

Fonte: Elaborado por Isabela Nogueira, a partir de UN Comtrade.

Nota: Venezuela depende da aprovação dos Congressos Nacionais dos diferentes paísesmembro para entrar no bloco. O país não consta na soma dos dados Mercosul. Dados de 2007 não disponíveis na data do levantamento. Quadro apresenta números de 2006. 
Do ponto de vista do processo de integração regional, é necessário considerar uma questão macroeconômica substantiva. O Brasil possui um PIB equivalente a mais de duas vezes o argentino, ou mais de dez vezes o peruano, ou cinco vezes o venezuelano. É evidente que se trata da economia nacional que, através de sua expansão, poderá exercer um efeito positivo para uma região integrada. Entretanto, devido às opções principais de política econômica, o Brasil tem sido a economia latino-americana que menos cresce nos últimos anos. Na década da integração, entre 1990-2000, a América Latina como um todo teve um crescimento bastante reduzido, fortemente influenciado pelo Brasil - que cresceu menos do que a média dos países. Na nova década, o baixo crescimento persistiu até a sua primeira metade, as inflexões na política econômica ocorridas nos últimos anos no país não alteraram substancialmente essa dinâmica regional. Por outro lado, devido ao seu maior grau de industrialização e menor crescimento, o Brasil vem apresentando crescentes saldos comerciais, com os todos os países da América do Sul, cujo comércio expandiu-se através das exportações de commodities para fora da região (Quadro 6).

\begin{tabular}{|l|l|l|l|l|l|l|l|}
\hline & $\mathbf{1 9 9 5}$ & $\mathbf{1 9 9 7}$ & $\mathbf{1 9 9 9}$ & $\mathbf{2 0 0 1}$ & $\mathbf{2 0 0 3}$ & $\mathbf{2 0 0 5}$ & $\mathbf{2 0 0 7}$ \\
\hline Argentina & -1.550 & -1.172 & -448 & -1.204 & -111 & 3.674 & 4.006 \\
\hline Paraguai & 784 & 889 & 484 & 420 & 232 & 642 & 1.214 \\
\hline Uruguai & 74 & -98 & 23 & 138 & -134 & 356 & 502 \\
\hline Venezuela & -413 & -369 & -512 & 348 & 333 & 1.968 & 4.378 \\
\hline Mercosul & -690 & -381 & 58 & -646 & -13 & 4.672 & 5.646 \\
\hline
\end{tabular}

Quadro 6 - Saldo Comercial do Brasil com os Países do Mercosul

Fonte: Elaborado por Isabela Nogueira a partir de MDIC e Comtrade.

Estas condições estruturais impedem que o país exerça, do ponto de vista econômico, um papel de locomotiva da economia regional.

Ao lado desta dimensão macroeconômica e estrutural, devido à sua localização geográfica e à precária infraestrutura, os países do Mercosul não se inseriram de forma significativa na produção compartilhada global $^{21}$ (UNCTAD, 2002). Se considerarmos o padrão de comércio prevalecente entre os países do bloco, observa-se (Quadro 7) o predomínio

21 No continente latino-americano, apenas o México e alguns países do Caribe inseriram-se na especialização vertical de trabalho, tal como descrita neste texto. Devido à sua proximidade com os EUA, os acordos de livre-comércio que o México estabeleceu no âmbito do Nafta e os que os países do Caribe estabeleceram com aquele país criaram de fato uma ampla integração produtiva. Esta, entretanto, foi fortemente assimétrica, na medida em que o conteúdo importado das exportações mexicanas e a ausência de políticas tecnológicas levaram a uma forte polarização da sua estrutura produtiva com baixo dinamismo econômico. 
no lado das importações de bens finais de consumo, bens de capitais e bens intermediários semifinais (matérias-prima) e numa proporção menor, partes e componentes. Esta é uma realidade bastante assimétrica entre os países. O Brasil, o país mais industrializado, apresenta uma proporção maior das importações em partes e componentes. Do lado das exportações, o percentual de partes e componentes é naturalmente muito mais baixo, tendo em vista a inexistência na região de países produtores especializados em bens com maior densidade tecnológica ou que participem da sua cadeia produtiva.

\begin{tabular}{|c|c|c|c|c|c|c|c|c|c|}
\hline Importações & & Brasil & Argentina & Paraguai & Uruguai & Venezuela* & Mercosul & EUA & Mundo \\
\hline & FC & 16,4 & 20,1 & 42,0 & 29,4 & 23,1 & 18,9 & 31,1 & 25,4 \\
\hline & FCA & 21,8 & 27,4 & 24,1 & 19,8 & 27,4 & 23,6 & 17,8 & 18,4 \\
\hline \multirow[t]{5}{*}{1998} & IMPC & 19,5 & 18,3 & 8,8 & 11,0 & 14,0 & 18,5 & 19,4 & 20,7 \\
\hline & IMSF & 29,2 & 29,8 & 16,0 & 30,8 & 29,4 & 29,1 & 19,7 & 26,3 \\
\hline & $\mathbf{P}$ & 9,6 & 3,2 & 3,3 & 7,5 & 4,7 & 7,3 & 6,8 & 5,9 \\
\hline & FC & 10,2 & 22,0 & 36,4 & 28,9 & 32,4 & 14,6 & 31,5 & 25,1 \\
\hline & FCA & 19,9 & 20,7 & 14,2 & 14,2 & 20,5 & 19,7 & 17,4 & 18,1 \\
\hline \multirow[t]{5}{*}{2001} & IMPC & 23,5 & 17,3 & 9,0 & 9,4 & 12,2 & 21,0 & 16,6 & 20,7 \\
\hline & IMSF & 30,2 & 34,7 & 22,3 & 32,5 & 28,6 & 31,2 & 18,7 & 24,9 \\
\hline & $\mathbf{P}$ & 10,9 & 3,8 & 4,1 & 13,1 & 4,5 & 9,0 & 9,4 & 7,0 \\
\hline & FC & 8,9 & 16,8 & 31,0 & 19,4 & 26,5 & 11,9 & 30,7 & 24,5 \\
\hline & FCA & 13,1 & 23,6 & 19,3 & 11,4 & 23,1 & 15,9 & 16,8 & 18,1 \\
\hline \multirow[t]{5}{*}{2004} & IMPC & 24,4 & 16,5 & 8,4 & 7,5 & 13,1 & 21,4 & 14,9 & 20,6 \\
\hline & IMSF & 32,8 & 36,0 & 23,7 & 35,2 & 31,9 & 33,3 & 19,6 & 25,1 \\
\hline & $\mathbf{P}$ & \begin{tabular}{|l}
17,4 \\
\end{tabular} & 4,5 & 3,7 & 24,0 & 4,8 & 14,0 & 12,0 & 7,7 \\
\hline & FC & \begin{tabular}{|l|}
11,2 \\
\end{tabular} & 17,8 & 27,6 & 21,6 & nd & 13,8 & 28,6 & nd \\
\hline & FCA & 15,0 & 23,1 & 24,7 & 15,1 & nd & 17,3 & 16,1 & nd \\
\hline \multirow[t]{3}{*}{2007} & IMPC & 21,4 & 18,1 & 12,2 & 7,1 & nd & 19,8 & 13,9 & nd \\
\hline & IMSF & 30,8 & 31,9 & 20,8 & 32,5 & nd & 30,8 & 19,3 & nd \\
\hline & $\mathbf{P}$ & 16,6 & 4,6 & 2,2 & 16,4 & nd & 13,1 & 15,1 & nd \\
\hline \multirow[t]{3}{*}{ Exportações } & & Brasil & Argentina & Paraguai & Uruguai & Venezuela* & Mercosul & EUA & Mundo \\
\hline & FC & 21,2 & 27,5 & 12,4 & 48,8 & 5,1 & 24,1 & 14,8 & 24,7 \\
\hline & FCA & 11,5 & 5,7 & 0,6 & 4,9 & 0,8 & 9,2 & 23,8 & 17,8 \\
\hline \multirow[t]{5}{*}{1998} & IMPC & 11,1 & 4,7 & 0,4 & 3,1 & 1,9 & 8,7 & 29,7 & 20,5 \\
\hline & IMSF & 35,6 & 34,5 & 29,0 & 33,7 & 19,4 & 35,1 & 22,1 & 26,5 \\
\hline & $\mathbf{P}$ & 18,7 & 24,5 & 57,5 & 9,1 & 48,6 & 20,7 & 5,4 & 6,7 \\
\hline & FC & 21,8 & 20,0 & 15,3 & 45,5 & 2,3 & 21,7 & 15,2 & 23,6 \\
\hline & FCA & 14,2 & 5,4 & 0,4 & 2,1 & 0,5 & 11,1 & 22,1 & 17,2 \\
\hline \multirow[t]{2}{*}{2001} & IMPC & 9,8 & 4,2 & 0,1 & 1,4 & 1,0 & 7,8 & 30,3 & 20,4 \\
\hline & IMSF & 32,7 & 36,8 & 24,0 & 41,3 & 12,4 & 34,0 & 22,7 & 24,6 \\
\hline
\end{tabular}


(continuação)

\begin{tabular}{|l|l|l|l|l|l|l|l|l|l|}
\hline & $\mathbf{P}$ & 17,2 & 27,6 & 60,2 & 8,3 & 60,1 & 20,6 & 5,0 & 9,3 \\
\hline & FC & 21,1 & 19,8 & 15,2 & 46,3 & 1,4 & 21,3 & 15,5 & 23,7 \\
\hline & FCA & 13,2 & 3,6 & 0,3 & 1,3 & 0,9 & 10,3 & 20,8 & 17,1 \\
\hline & IMPC & 8,8 & 4,3 & 0,2 & 1,6 & 0,9 & 7,4 & 27,9 & 20,4 \\
\hline & IMSF & 34,2 & 40,4 & 32,6 & 33,4 & 11,6 & 35,8 & 24,6 & 26,1 \\
\hline & P & 19,2 & 24,5 & 51,7 & 12,9 & 85,2 & 20,8 & 6,1 & 7,6 \\
\hline & FC & 19,3 & 21,1 & 18,3 & 43,9 & nd & 20,2 & 16,2 & nd \\
\hline & FCA & 12,4 & 6,1 & 0,7 & 1,6 & nd & 10,5 & 21,4 & nd \\
\hline & IMPC & 8,6 & 4,4 & 0,7 & 2,5 & nd & 7,3 & 23,9 & nd \\
\hline & IMSF & 31,5 & 39,3 & 29,1 & 33,4 & nd & 33,5 & 25,2 & nd \\
\hline
\end{tabular}

Quadro 7 - Padrão de Comércio dos Países do Mercosul segundo Categoria de Bens

Fonte: Elaborado por Isabela Nogueira a partir de UN Comtrade.

Notas: Metodologia de agregação utilizada por Aminian, Fung e lizaka (2007) com base no sistema de classificação de produtos BEC (Broad Economic Categories) divulgado pela UN Comtrade. FC: Bens Finais de Consumo, FCA: Bens Finais de Capital, IMPC: Bens Intermediários (Partes e Componentes), IMPSF: Bens Intermediários (semifinais), P: Bens Primários.

Uma exceção parcial desta realidade foi a desenvolvida na indústria automobilística, que após uma década marcada por forte expansão do comércio intrarregional e conflitos de interesses entre Brasil e Argentina, decorrente das mudanças no câmbio e regime macroeconômico, construíram, no início do milênio, um regime especial de comércio. Este incluiu a redução de tarifas em partes e componentes e de conteúdo doméstico e estipulou mecanismos de compensação bilateral. Esta indústria, formada essencialmente por subsidiárias de EMNs de fora da região, tanto na montagem quanto no suprimento de partes e componentes, ${ }^{22}$ passou a construir uma divisão vertical do trabalho e novos clusters produtivos no sudeste brasileiro e norte argentino, com o Brasil afirmando-se como um exportador líquido de partes e componentes produzidos por subsidiárias de empresas globais.

O contraste com a realidade asiática não poderia ser mais evidente. Entretanto, o Mercosul tem sido um poderoso arranjo para a expansão das exportações industriais e, em particular das mais intensivas em tecnologia (UNCTAD, 2007). O comércio regional tem favorecido uma maior diversificação produtiva do que o comércio global, ainda que esta mudança tenha beneficiado especialmente a indústria brasileira. Neste

22 Para uma análise dos principais grupos econômicos no setor, ver Uallachain e Wasserman (1999). 
sentido, devido ao seu tamanho relativo e à assimetria no conteúdo tecnológico da produção, a expansão do Mercosul depende em grande parte de um desenho articulado de políticas industriais voltado a induzir maior expansão dos mercados industriais e de serviços especializados para os países de menor grau de desenvolvimento, o que requer, como se observou, uma taxa de crescimento maior do Brasil.

\section{Considerações Finais}

A possibilidade da modularização de processos produtivos em diversas indústrias e, em particular, em máquinas elétricas e eletrônicas, e do monitoramento e controle de atividades dispersas em diferentes locais permitiu o fatiamento e a distribuição da cadeia produtiva segundo critérios de custo e exploração de economia de escalas. Através da integração produtiva, vários países de menor grau de desenvolvimento podem contar com maior acesso aos mercados externos e possibilidades de exportação e crescimento. Não há, entretanto, qualquer automatismo que garanta esta integração produtiva virtuosa. Observou-se que o aumento do conteúdo importado das exportações fez com que a expansão da corrente de comércio, induzida pela integração produtiva, pudesse resultar em maiores restrições externas ao crescimento econômico e, no limite, uma reversão das importações e, consequente, redução da integração e especialização produtiva. Por outro lado, devido à assimetria da distribuição de valor da cadeia produtiva, os países de menor grau de desenvolvimento puderam ficar aprisionados em atividades de baixo valor e alta concorrência com escassas possibilidades de deslocarem sua estrutura produtiva.

Evidenciou-se neste texto a singularidade da experiência asiática e analisou-se como a conjugação de fatores estruturais, macroeconômicos e microeconômicos no leste e sudeste asiático promoveram uma integração produtiva virtuosa com um elevado grau de crescimento econômico regionalmente articulado, ainda que com significativas assimetrias na apropriação do valor e do progresso técnico. Utilizou-se uma versão do esquema dos gansos voadores (EGV), incorporando fatores de demanda e descreveu-se a dinâmica da integração produtiva asiática a partir das seguintes características: (i) a formação de uma triangulação entre países especializados e produtores de Original Equipment Machine, partes e componentes (como Japão, Coreia do Sul, Taiwan), países montadores de atividades industriais padronizadas e intensivas em mão de obra (China e países da Asean-4) e um grande mercado consumidor final e importador líquido da produção industrial regional (EUA e nos 
anos mais recentes a China); (ii) reduzida volatilidade da taxa real de câmbio (pré e pós-crise de 1997) com o dólar como moeda chave e taxa real de câmbio compatível com a competitividade externa; (iii) a formação de uma hierarquia de países ordenados de forma similar, tanto por grau de industrialização quanto por custo de trabalho em dólar (taxa real de cambio); (iv) políticas tecnológicas variadas, particularmente agressivas no Japão, entre os Tigres Asiáticos e recentemente na China; (v) a existência na região de centros financeiros e de serviços altamente especializados (Hong Kong, Cingapura); (vi) predomínio dos investimentos asiáticos na montagem da rede de produção compartilhada; (vii) grande proximidade geográfica e acesso ao mar entre os principais países asiáticos e relativa proximidade dos centros consumidores finais.

A partir desta experiência, foram evidenciados alguns aspectos que poderiam ser considerados no que tange a integração produtiva no âmbito do Mercosul. Argumentou-se que o baixo grau de integração nesta região é principalmente decorrente de fatores estruturais, macroeconômicos e microeconômicos. O predomínio de commodities primárias e atividades intensivas em recursos naturais, o atraso nas indústrias de máquinas elétricas e eletrônicas, a inexistência de produtores especializados de OEM, o predomínio de subsidiárias de empresas multinacionais sediadas fora da região, a inexistência de uma gradiente de conteúdos tecnológicos articulada com a do custo do trabalho entre países, e os elevados custos de transportes são evidentes explicações de corte estrutural. Entretanto, algumas transformações favorecedoras a uma maior integração produtiva poderiam se desenvolver a partir da consolidação do comércio intrarregional, na medida em que este viabilizasse uma maior diversificação produtiva e industrialização, sobretudo dos países de menor grau de industrialização. O problema da região, como pode ser imediatamente contrastado com a experiência asiática, diz respeito à composição da pauta exportadora regional, a vulnerabilidade externa de cada país do bloco - e sua consequente influência sobre a elevada volatilidade da taxa real de câmbio - e à inexistência de um importador líquido de dentro ou de fora do bloco que pudesse viabilizar a expansão de uma corrente de comércio que fosse compatível com a expansão em simultâneo do crescimento econômico regional. 


\section{Referências}

AKAMATSU, K. A historical pattern of economic growth in developing countries. Journal of Developing Economies, v. 1, n. 1, p. 3-25, mar.-aug. 1962.

AMINIAN, N.; FUNG, K. C.; IIZAKA, H. Foreign direct investment, intra-regional trade and production sharing in East Ásia Discussion Papers Series, 07 E 064, Research Institute of Economy, Trade and Industry (RIETI), Tóquio, Japão, 2007.

CHUDNOVSKY, D.; FANELLI, J. M. Introdución: el desafio de integrarse para crecer In: CHUDNOVSKY, D.; FANELLI, J. M. (Org.). El Desafio de integrarse para crecer: balance y perspectivas del Mercosur em su primera década. Buenos Aires: Siglo Veintiuno, 2001.

FEENSTRA, R. Integration of trade and disintegration of production in the global economy. Journal of Economic Perspectives, v. 12, n. 4, p. 31-50, 1998.

GAULIER, G.; LEMOINE, F.; KESENCI, D. China integration in Asian production networks and its implications. Discussion Papers Series, 04 E 033, Research Institute of Economy, Trade and Industry (RIETI), Tóquio, Japão, 2004.

GINZBURG, A.; SIMONAZZI, A. Patterns of industrialization and the flying-geese model: the case of electronics in East Asia. In: CONFERENCE IN HONOR OF PROFESSOR SEBASTIANO BRUSCO, Modena, Italy, sep. 2003.

GROSSMAN, G. M.; HELPMAN, E. Outsourcing in global economy. Review of Economic Studies, v. 72, n. 1, p. 135-159, jan. 2005.

HEINTZ, J. Low-wage manufacturing and global commodity chains: a model in the unequal Exchange tradition. Cambridge Journal of Economics, v. 30, n. 4, p. 507-520, 2006.

HUMMELS, D.; RAPOPORT, D.; YI, K. M. Vertical specialization and the changing nature of world trade. Federal Reserve Bank of New York Economic Policy Review, v. 4, n. 2, p. 79-99, 1998.

KASAHARA, S. The flying feese paradigm: a critical study of its application to East Asian Regional Development. Discussion Paper: UNCTAD, n. 169, 2004.

KOJIMA. K. The flying geese model of Asian Economic Development: origin theoretical extensions and regional policy implications Journal of Asian Economics v. 11, n. 4 , p. 375-401, 2000.

KWAN, $\mathrm{H}$. The rise of China and Asia's flying-geese pattern of economic development: an empirical analysis based on US Import Statistics, Rieti Discussion Paper Series, n. 2, v. 009, 2002.

MCKINNON, R.; SCHNABL, G. China: a stabilizing or deflationary influence in East Asia? The problem of conflicted virtue. Working Papers n. 03007, Stanford University, Department of Economics in its series, 2003.

MEDEIROS, C. Globalização e a inserção internacional diferenciada da Ásia e da América Latina. In: TAVARES, M. C; FIORI, J. L. (Org.). Poder e dinheiro. São Paulo: Vozes, 1997.

. A China como um duplo polo na economia mundial e a recentralização asiática $\overline{\text { Revista }}$ de Economia Política v. 26, n. 3, p. 381-400, jul.-set. 2006.

MIT. White paper on international economy and trade. Ministério da Economia, Comércio e Indústria do Japão, 2007. 
NICITA, A.; OLARREAGA, M. Trade, Production and Protection 1976-2004, World Bank Economic Review v. 21, n. 1, p. 165-171, 2007.

PREBISCH, R. El Mercado Común Latinoamericano. In: GURRIERI, A. La obra de Prebisch en la CEPAL, n. 5, p. 1-8, 1959. Tomo IX.

ROWTHORN, R. East Asian development: the flying geese paradigm reconsidered, Study: UNCTAD, n. 8, 1996.

SAKAKIBARA; YAMAKAWA. Regional integration in East Asia: challenges and opportunities. Working Paper n. 3078, 2003

STEINFELD, E. China's shallow integration: networked production and the new challenges for late industrialization. World Development, v. 32, n. 11, p. 1971-1987, 2004.

SUN, Y. Sources of innovation in China's manufacturing sector: imported or developed in-house, Environment and Planning A, v. 34, n. 6, p. 1059-1072, 2002.

TUNG. A. C. Beyond flying geese: the expansion of East Asia's Eelectronics trade. German Economic Review, v. 4, n. 1, p. 35-51, 2003.

UALLACHAIN, B.; WASSERMAN, D. Vertical integration in a lean supply chain: brazilian automobile componente parts, Economic Geography, v. 75, n. 1, p. 21-42, 1999.

UNIDET NATIONS CONFERENCE ON TRADE AND DEVELOPMENT - UNCTAD. Trade and Development Report. New York; Geneva: UNCTAD, 2002.

. Trade and Development Report. New York; Geneva: UNCTAD, 2007.

\section{Sites consultados}

Bank for International Sttlements (BIS) Statistics <http://www.bis.org/statistics/index. htm>

Brasil. Ministério do Desenvolvimento, Indústria e Comércio Exterior <http://www. mdic.gov.br>

International Monetary Fund - IMF. Data and Statistics < http:/www.imf.org/external/ data.htm>

Taiwan. Bureau of Foreign Trade < http://eweb.trade.gov.tw/ $>$

UN Comtrade <http://comtrade.un.org >

Recebido em: 27/05/2010.

Aceito em: 10/09/2010. 